\title{
A produção de sentidos por estudantes a partir de um vídeo educativo na educação em enfermagem
}

\author{
The meaning-making by students \\ From an educational video in nursing education
}

Américo de Araujo Pastor Junior ${ }^{1}$

Luiz Augusto Coímbra de Rezende Filho ${ }^{2}$

Cláudia Mara de Melo Tavares ${ }^{3}$

\section{Resumo}

Partimos da percepção dos usos recorrentes de filmes e vídeos nos espaços de formação em enfermagem são orientados e fundamentados em ideias pouco pesquisadas empiricamente. Com base nos estudos culturais, o presente artigo apresenta os resultados de um estudo sobre o uso de um vídeo educativo em uma dinâmica formativa de enfermagem. Para isso analisamos conjuntamente a obra, a produção e os sentidos produzidos por espectadores. Os resultados, de modo geral, indicam que os espectadores seguiram às leituras esperadas para o vídeo, que foi construído para valorizar e orientar

\footnotetext{
${ }^{1}$ Professor Adjunto do Instituto de Biodiversidade e Sustentabilidade da Universidade Federal do Rio de Janeiro. Possui doutorado e mestrado em Educação em Ciências e Saúde pelo Núcleo de Tecnologia Educacional para a Saúde (NUTES-UFRJ), bacharelado em Psicologia pela Universidade Católica de Petrópolis e bacharelado em Desenho Industrial (Design Programação Visual) (UFRJ).

${ }^{2}$ Professor Associado I do Programa de Pós-Graduação em Educação em Ciências e Saúde do NUTES-UFRJ. É docente colaborador credenciado no Programa de PósGraduação em Cinema da UFF. Possui graduação em Cinema pela Universidade Federal Fluminense (1995), mestrado em Comunicação pela Universidade Federal do Rio de Janeiro (2000) e doutorado em Comunicação pela Universidade Federal do Rio de Janeiro (2005). Foi coordenador do Programa de Pós-Graduação em Educação em Ciências e Saúde do NUTESUFRJ.

3 Professora Titular do Departamento de Enfermagem Materno-Infantil e Psiquiatria da Escola de Enfermagem da Universidade Federal Fluminense. Graduação em Enfermagem pela Universidade Federal do Rio de Janeiro (1989). Mestre em Educação (Currículo) pela Pontifícia Universidade Católica de São Paulo (1995), Doutora em Enfermagem pela Universidade Federal do Rio de Janeiro (1998) e pós-doutorado pela Universidade de São Paulo - USP (2011). Ensina em todos os niveis (graduação, especialização, mestrado e doutorado).
} Interfaces da Educ., Paranaíba, v.11, n.31, p. 606 - 624, 2020 
A produção de sentidos por estudantes...

sobre a consulta de enfermagem, contudo esses sujeitos articularam os sentidos produzidos com suas experiências e transcenderam as expectativas didáticas do audiovisual o utilizando como recurso para discutir e refletir sobre suas formações, desafios profissionais e obstáculos políticos da produção do cuidado no serviço de saúde.

Palavras-chave: Educação em Enfermagem. Filmes e Vídeos Educativos. Tecnologia Educacional.

\begin{abstract}
In this study, we start from the perception of the recurrent uses of movies and videos in nursing training spaces are oriented and based on ideas poorly researched empirically. Based on cultural studies, the present article presents the results of a study on the use of an educational video in a context of nursing training. Consistent with this, we jointly analyze the work, the production and the meanings produced by viewers. The results, in general, indicate that viewers followed the expected readings for the video, which was built to value and guide the nursing consultation, however, these subjects articulated the senses produced with their experiences and transcended the didactic expectations of audiovisual use as a resource to discuss and reflect on their formations, professional challenges and political obstacles to the production of care in the health service.
\end{abstract}

Key-words: Education. Nursing. Instructional Films and Videos. Educational Technology.

\title{
Introdução
}

A formação em enfermagem vem se deparando com desafios que apontam para a necessidade do desenvolvimento integral do profissional, envolvendo aspectos objetivos de sua atuação (competências técnicas), bem como aspectos subjetivos relacionados a sua história, emoções e relações. De acordo com Silva e Tavares (2004), os profissionais de saúde precisam estar capacitados profissional, técnico, psicológico, politico e humanisticamente. Interfaces da Educ., Paranaíba, v.11, n.31, p. 606 - 624, 2020 
Américo de Araujo Pastor Junior, Luiz Augusto Coímbra de Rezende Filho e Cláudia Mara de Melo Tavares

Estas demandas nem sempre são atendidas, apesar de estarem presente nos documentos orientadores das práticas educacionais, não são devidamente valorizadas pelo mercado.

Uma forma que a academia vem encontrando para responder à parte desses desafios por formação humanizada é a utilização de vídeos e filmes nas aulas. Tavares et al. (2014), por exemplo, indica como os filmes podem ser utilizados na formação em enfermagem como facilitadores se aprendizados teóricos, bem como recursos para a experimentação, por universitários, de práticas sociais e culturais. Os autores ainda destacam como uma obra cinematográfica pode despertar interesses, trazer à tona questões não conhecidas, romper as barreiras do aprendizado tecnicista, da racionalidade do discurso estritamente cientificista, desenvolver reflexões sobre o cotidiano profissional e contribuir para o desenvolvimento no aluno de recursos para lidar com diversas situações de produção de cuidado. Oliveira et al. (2012) acrescenta que os filmes oferecem a possibilidade de aproximação dos estudantes a contextos de atendimento nos quais os acadêmicos não têm muito referencial de vivência, além de serem fontes de experiências emocionais e cognitivas que permitem ampliar a visão de mundo e aperfeiçoar competências necessárias à formação em enfermagem.

Em revisão por nós desenvolvida, e aceita para a publicação na Revista Brasileira de Enfermagem, identificamos algumas tendências no uso de vídeos e filmes na formação em enfermagem. Uma primeira tendência foi o uso de vídeos como meio de treinar enfermeiros para a realização de procedimentos (HEWITT et al., 2015) e para a comunicação com o paciente (BARRAT, 2010). O uso de filmes foi recorrente como estratégia de sensibilização, conscientização e reflexão (FIESCHI et al., 2010). Em ambos, havia o objetivo de as mídias serem estímulos e terem como resultado um comportamento, percepção e ou determinado conhecimento a ser produzido pelos estudantes espectadores.

Entendimentos como esses, que frequentemente fundamentam o uso de audiovisuais na educação, estão baseados em pressupostos que apresentam alguns aspectos problemáticos. Worth (1974), já nessa data questionava a insuficiência de estudos empíricos que sustentassem esses argumentos sobre Interfaces da Educ., Paranaíba, v.11, n.31, p. 606 - 624, 2020 
A produção de sentidos por estudantes...

as potencialidades das imagens em seu uso na educação. Para o autor, esses argumentos, em geral, são sustentados pela crença da universalidade das imagens para comunicar a diferentes culturas, idades e gêneros, e superioridade psicológica e social das imagens em comunicar ("uma imagem vale mais que mil palavras").

Outro aspecto diz respeito ao modelo de comunicação subjacente aos argumentos questionados. Isso pois, baseando-se na critica feita por Stuart Hall (2003) ao modelo tradicional (emissor-mensagem-receptor) de comunicação, nesses argumentos transparece o entendimento da comunicação como algo unilinear e pressupõe, assim, a passividade dos espectadores/receptores. Isso fica claro quando os vídeos são entendidos como estímulos capazes de motivar, provocar reflexões, ou mesmo substituir uma experiência em algum contexto profissional. Sob essa perspectiva, caberia aos estudantes espectadores a simples assimilação de conteúdos transmitidos via o audiovisual, consistindo em dinâmica comportamentalista de estímulo/resposta. Em resposta a isso, Hall propõe pensar a comunicação em sua complexidade, multilineariadade e, principalmente, entendendo os espectadores como ativos na produção de sentidos de suas experiências a partir do filme/vídeo.

Um caminho para atender a essa demanda e superar esses obstáculos nos saberes orientadores das práticas educacionais com vídeos e filmes na formação em enfermagem, é realizar estudos empíricos que envolvam tanto o estudo da produção (produtores e obras audiovisuais), como a recepção (estudo dos espectadores em sua relação com as obras). Recentemente, na educação médica, realizamos alguns estudos com esse propósito (PASTOR JUNIOR et al., 2016). Os resultados demonstraram que os estudantes tenderam a negociar os sentidos produzidos por eles sobre os filmes assistidos e mobilizaram saberes produzidos na disciplina em que assistiram a obra para produzir esses sentidos, e extrapolaram as expectativas de leituras desejadas pelos professores para a atividade, bem como as expectativas dos produtores para a obra. Além disso, entre outros resultados, observamos que os estudantes adquiriram voz para reivindicar por explicações sobre tópicos pouco valorizados por professores. Ou seja, o uso de filme rompeu com o Interfaces da Educ., Paranaíba, v.11, n.31, p. 606 - 624, 2020 
Américo de Araujo Pastor Junior, Luiz Augusto Coímbra de Rezende Filho e Cláudia Mara de Melo Tavares

aprisionamento dos planos de aula e currículo e aproximou as aulas das demandas dos estudantes, espectadores ativos na produção de sentidos.

Diante disso, torna-se relevante a realização de pesquisas de base empírica sobre os usos vídeos e filmes da educação em enfermagem, que incluam estudar tanto o polo da produção quanto a da recepção. Para isso, o presente artigo apresenta uma pesquisa que teve por objetivo caracterizar e refletir sobre a dinâmica de uso de uso de um vídeo educativo na formação em enfermagem, considerando tanto o polo da produção quando o da recepção. O vídeo educativo utilizado, Consulta de Enfermagem (NUTES, 1992), volta-se a encenação de uma dinâmica de atendimento em enfermagem.

\section{Quadro teórico-metodológico}

Para realizar estudos sobre usos de audiovisual em dinâmicas de ensino e aprendizagem, baseamo-nos centralmente no aporte teórico dos Estudos Culturais (principalmente na Escola de Birmigham), sobretudo no nas obras de Stuart Hall, David Morley, Elizabeth Ellsworth, Kim Schrøder e Jay Lemke.

A partir da crítica ao modelo tradicional de comunicação (unilinear e unidirecional), Hall (1973) propõe pensar a comunicação como um processo de circularidade, em que emissores e receptores produzem sentidos ativamente, influenciados diretamente por seu alinhamento ideológico. Como desdobramento dessa proposta, Hall desenvolve o Modelo Codificação/Decodificação, como uma tentativa de pensar o processo comunicativo como um circuito não fechado de produção, circulação, distribuição/consumo e reprodução de sentidos/significados.

Sob essa perspectiva, entende-se que as atividades sociais humanas são desenvolvidas no interior de enquadramentos institucionais e culturais, e que, portanto, produção de sentidos é interdependente às dinâmicas sociais que produzimos e nas quais estamos inseridos (LEMKE, 2005). Schrøder et al. (2003) acrescenta que os usos que fazemos das mídias estão ancorados no contexto do cotidiano em que vivemos nossas vidas como um membro de uma parcial sobreposição de grandes e pequenos grupos. Desse modo, de acordo com o autor, os indivíduos possuem recursos socioculturais que os permitem Interfaces da Educ., Paranaíba, v.11, n.31, p. 606 - 624, 2020 
A produção de sentidos por estudantes...

criar seus próprios sentidos para as suas próprias experiências, desafiando assim à estrutura social determinante/hegemônica, ainda que as disputas culturais possam ser desiguais entre grupos dominantes e oprimidos. Nesse sentido, os estudos de audiência produzidos nessa perspectiva, envolvem necessariamente o estudo dos textos como uma tentativa de prescrição de leituras e estudo das leituras efetivamente feitas pelos receptores desses textos, imersos em suas práticas cotidianas de produção de sentido.

Considerando que a dinâmica comunicacional é, então, uma dinâmica de negociação de sentidos, Hall destaca que os produtores adotam estratégias na construção de seus produtos de comunicação que buscam, ao máximo, controlar os sentidos produzidos pelos espectadores. Uma dessas formas é tentar determinar o que deve ser entendido e outra é oferecer papeis/pontosde-vistas a partir dos quais os espectadores devem significar o produto e, então produzir os sentidos esperados. A primeira forma diz respeito aos conceitos de significado preferencial (HALL, 1973) e a segunda trata-se de Modo de Endereçamento (ELLSWORTH, 2001). Assim, o significado preferencial consiste de uma recomendação leia-me desta forma, e o Modo de Endereçamento de um entendimento de quem o produtor pensa que é o espectador e de quem ele quer que o espectador seja na relação com o produtor. Portanto, em se tratando de filmes e vídeos na educação, o Significado Preferencial é uma tentativa de fixar uma determinada (no universo de leituras possiveis no audiovisual enquanto polissemia estruturada) e Modo de Endereçamento uma forma de abordar um público específico e lhes oferecer papeis/perspectivas de leitura. Autora indica que o modo de endereçamento pode ser estudado voltando-se as três seguintes questões: Quem o filme pensa que o espectador é? Quem o filme quer que ele seja? Quem o espectador pensa que é?

Schrøder et al. (2000) questiona a ênfase dada por Hall às questões ideológicas e a consequente unidimensionalidade deste modelo. Em resposta, o autor desenvolve um modelo complexifica o modelo proposto por Hall, propondo trabalhar com diferentes dimensões subjetivas e "objetivas" de leituras e implicações das leituras, o Modelo Multidimensional de análise da recepção. Este modelo é constituído por seis dimensões analíticas de recepção: Interfaces da Educ., Paranaíba, v.11, n.31, p. 606 - 624, 2020 
Américo de Araujo Pastor Junior, Luiz Augusto Coímbra de Rezende Filho e Cláudia Mara de Melo Tavares

quatro dimensões de leitura (motivação, compreensão, discriminação, posição) e duas dimensões de implicação (avaliação e implementação). As primeiras dizem a respeito das experiências subjetivas em que o significado é produzido em um contexto mais específico. As segundas dizem respeito a como estes sentidos produzidos a partir da leitura são usados como recursos para uma ação política em um contexto sócio, político e ideológico de significação social.

Mediante ao quadro teórico apresentado, optamos por um desenho metodológico que buscou dar conta destes processos nos três níveis constituintes da abordagem holística em que a produção e a recepção são pesquisados conjuntamente. Para isso, realizamos análise filmica do vídeo a fim de caracterizar o significado preferencial e modo de endereçamento. Em um segundo momento procedemos com uma exibição experimental seguida de discussão semiestruturada com um grupo de 10 enfermeiros, a fim de poder caracterizar as suas leituras na dimensão de compreensão, posição e discriminação. De acordo com de acordo com Rezende Filho et al. (2015), a dimensão, A dimensão compreensão diz respeito à forma como os espectadores entendem o material audiovisual, sob influência dos contextos micro e macrossociais, e suas posições de leitura vão da divergência (polissemia total) à convergência (monossemia total). Já a dimensão de discriminação refere-se a como os espectadores podem adotar uma posição mais ou menos esteticamente crítica frente ao texto filmico (imersão), e como e o quanto uma leitura está caracterizada pelo nível de consciência do espectador sobre o caráter de construção e de artifício do produto audiovisual (distanciamento). Esta dimensão compreende dois eixos paralelos em continuum. Um vai da não imersão a imersão total, o outro do não distanciamento ao distanciamento total. A dimensão posição refere-se ao nivel ideológico (subjetivo) do espectador, e está relacionada à atitude ideológica pessoal/subjetiva de aceitação, negociação ou rejeição do texto por parte do espectador.

No presente estudo, utilizamos o vídeo educativo Consulta de Enfermagem (22min). Esse vídeo foi produzido, em 1990, pelo Núcleo de Tecnologia Educacional para a Saúde da Universidade Federal do Rio de Janeiro. Nesse vídeo, ao encenar um caso de tuberculose durante a gravidez, Interfaces da Educ., Paranaíba, v.11, n.31, p. 606 - 624, 2020 
A produção de sentidos por estudantes...

é enfatizado a importância da consulta de enfermagem, bem como o papel social do enfermeiro.

Os sujeitos dessa pesquisa são 10 enfermeiros de diferentes níveis de formação (estudantes de graduação, mestrandos, doutorandos a professores de ensino superior). Desses sujeitos, oito mulheres e dois homens, todos estão vinculados a mesma escola de enfermagem. Os participantes tiveram suas reações observadas durante a exibição do vídeo e discutiram o filme por pouco mais de uma hora. A discussão foi gravada, transcrita e analisada segundo a Análise de Conteúdo de Bardin (2008).

Essa pesquisa foi aprovada pelo comitê de ética em pesquisa competente sob o registro CAAE: 07677213.7.0000.5257. Os sujeitos consentiram a sua participação na pesquisa por concordância e assinatura do termo de consentimento livre e esclarecido.

\section{Resultados e discussão}

3.1 Estudo da produção - análise fílmica

O vídeo educativo Consulta de Enfermagem ${ }^{4}$ foi produzido em 1990 pelo NUTES/UFRJ e pela Ministério da Saúde, no contexto da Campanha Nacional Contra a Tuberculose. No ano de gravação do vídeo já havia um esforço da área da saúde na superação do modelo centrado no médico e implementação do SUS. A $8^{a}$ Conferência Nacional de Saúde, que havia ocorrido alguns anos antes, preconiza a mudança no modelo médico-centrista. Essa perspectiva é valorizada no vídeo, ou seja, mudanças no modo de cuidado e organização do sistema de saúde.

O vídeo de 22 minutos traz uma narrativa centrada na história de uma recém-formada enfermeira, Lúcia, que começa a trabalhar em um posto de saúde em uma região pobre. Além dos desafios de seu desenvolvimento profissional, a profissional precisa lidar com a realidade e obstáculos do serviço de saúde pública, sobretudo no combate à tuberculose. Insegura,

${ }^{4}$ Disponivel em: https://youtu.be/ErH6AmMoHjk Interfaces da Educ., Paranaíba, v.11, n.31, p. 606 - 624, 2020 
Américo de Araujo Pastor Junior, Luiz Augusto Coímbra de Rezende

Filho e Cláudia Mara de Melo Tavares

inexperiente e a assustada com o cenário caótico do serviço, Lúcia vai aprender a lidar com suas angústias, entender como funciona o trabalho interdisciplinar de atendimento em saúde, como melhor realizar a consulta de enfermagem, reconhecer as demandas do serviço público de saúde, as contribuições que a enfermagem pode ofertar e melhor entender os procedimentos de atendimento e tratamento de pacientes com tuberculose.

Nessa dinâmica, outros profissionais trazem falas orientadoras à protagonista. Primeiro o seu colega de trabalho traz falas com as do exemplo a seguir, em um desabafo durante o almoço:

\footnotetext{
Colega - Então, como é que foi de estreia?

Lúcia -Péssima.

Colega - Péssima?

Lúcia - Primeira consulta, uma grávida. Pode?

Colega - Mulheres ficam grávidas. Qual o problema?

Lúcia - O problema é que essa mulher tá com tuberculose. É, tenho certeza! Ai, a consulta foi um desastre! Coitada! Eu só consegui recolher o material para o exame e olhe lá!

Colega - É assim com todo mundo. A primeira consulta como toda estreia é imprevisivel, ninguém escapa. Ninguém esquece a teoria. O negócio é você não se abater e ter calma para as próximas.

Lúcia - O problema foi esse. Olha, eu fiquei tão nervosa mais tão nervosa, que eu não consegui nem olhar pra mulher. Será que eu não conferi bem os dados do prontuário? Sabe que eu não deitei a mulher? Você sabe que eu nem tirei a temperatura da mulher? Não fiz nada! Nada! Só conseguia pensar em colher o escarro, só isso. (suspiro). Eu acho que eu fiquei com medo dela, foi isso, medo.

Colega - Tá melhorando. Já sabe até que foi medo! O negócio é você relaxar e olhar o paciente de uma forma completa como quem tem um emprego, uma casa, um trabalho, uma vida inteira pode estar adoecendo a pessoa. É fundamental você olhar o paciente de uma forma integral, total.

Lúcia - Teoricamente eu sei. A gente tem que sempre que discutir as formas de tratamento com o paciente, o quadro geral, eu sei disso. $O$ problema é que ela vai voltar pra semana e eu ainda não sei como é que eu vou poder atendê-la melhor.
}

Nesse trecho, a personagem transparece toda a sua insegurança ao colega que a acalma e a ajuda a resolver o problema. As falas dela parecem buscar facilitar a identificação com essa personagem de um potencial espectador. Já a voz do colega, assemelha-se a de um professor. Essa mesma postura docente ocorre na fala da médica responsável pelo setor de exames pré-natais, que busca orientar a protagonista no trecho a seguir.

Médica - Está aqui a pasta dela. Maria Silvia dos Santos Gouveia. Casada, 36 anos, quatro filhos, comerciária. Está na vigésima semana. Aliás, o Dr. Joaquim à encaminhou para a pneumologia. Ela é muito fácil 
A produção de sentidos por estudantes...

de ser ajudada. Puxa conversa com ela e deixa ela falar. Você vai ver como é fácil conquistar a confiança dos pacientes. É só ter calma e saber escutar.

Lúcia - É claro, claro! Você deixa essa pasta comigo? Ótimo, agora me conta melhor, como é que é isso de conquistar a confiança dos clientes? Médica - As pessoas ficam mais felizes, e se gostam de quem trata delas, entendeu? Quer dizer, elas ficam mais a vontade, mais confiante na gente.

A médica pré-natal traz informações sobre como a enfermeira deve desenvolver seu trabalho, se relacionar com os pacientes e com a equipe multiprofissional, aspectos que guardam relação estreita com o significado preferencial da obra. Esse aspecto é reforçado pela frase na cartela final do vídeo: "a consulta de enfermagem é parte importante do trabalho multiprofissional nos serviços de saúde, com um forte componente educativo para os clientes e a comunidade". Na cena final, em que os diversos profissionais envolvidos no atendimento realizam uma reunião, há uma seria de falas que contribuem para o melhor entendimento do significado esperado para o vídeo. Por exemplo, o médico chefe expressa a sua satisfação por haver uma profissional de enfermagem realizando consultas no setor de pneumologia, destacando a importância desse atendimento para a melhoria do serviço. Assim, além de retratar aspectos da realidade do serviço de saúde, o vídeo parece ter o propósito de demonstrar a importância da consulta de enfermagem, os desafios enfrentados pelos profissionais de enfermagem para esse atendimento, bem como indica meios de superação de alguns obstáculos.

Diante disso, é possivel dizer que o significado preferencial do vídeo pode ser expresso da seguinte forma: A consulta de enfermagem traz uma importante contribuição na produção de cuidado em saúde à população, mas nem sempre o enfermeiro está preparado para esse desafio. Por esse motivo, ele deve colaborar com toda a equipe multidisciplinar e pacientes.

A insegurança demonstrada pela protagonista é um aspecto importante da narrativa e parece favorecer a abordagem de espectadores que se sentem do mesmo modo, ou seja, possivelmente estudantes (quando ela está insegura, fala: - Que saudades da sala de aula!) e profissionais de enfermagem recémformados. Esses espectadores, ao se identificarem com a protagonista, poderiam melhor vivenciar aspectos que a narrativa busca dar destaque, 
Américo de Araujo Pastor Junior, Luiz Augusto Coímbra de Rezende Filho e Cláudia Mara de Melo Tavares

sobretudo a percepção e superação dos obstáculos postos pela realidade do serviço de saúde. Nesse sentido, é possivel afirmar que, com relação ao modo de endereçamento, o vídeo foi produzido buscando abordar a profissionais de saúde iniciantes e estudantes, principalmente de enfermagem, e espera que estes consigam ter uma melhor percepção da realidade do atendimento, bem como aprender meios superar obstáculos postos a sua atuação nesses contextos.

\subsection{Estudo da recepção}

Durante a exibição do vídeo, os espectadores desenvolveram alguns comportamentos de aparente resistências a aspectos estéticos do filme. Vestuários e cenários que revelam o contexto temporal do vídeo, efeitos sonoros e visuais datados, e algumas falas dos personagens, provocaram risos na maior parte dos espectadores. Essas falas observadas se relacionam com a identidade do profissional de enfermagem e ocorreram durante o trecho do vídeo em que a protagonista não aceitou ser chamada de doutora por uma paciente ("eu não sou doutora, sou enfermeira"). O modo como a enfermeira comunica o diagnóstico de tuberculose à paciente também provocou muitos risos (“deu positivo"). Para os espectadores essa postura não pareceu coerente com a imagem que eles possuem de enfermeiro.

Na discussão, após a exibição, a maior parte das falas foram feitas tendo como base as experiências profissionais de quem discutia. A o universo filmico foi comparado ao universo das próprias experiências dos espectadores a todo momento. Os trechos transcritos a seguir exemplificam esse aspecto.

P2 - Bem, eu achei [o vídeo] um nivel muito atual... embora tenha me formado há um tempo, ... ainda hoje fazemos uma visita nas comunidades...

P5 - Ah, essa angústia dela também, eu tô lembrando da necessidade que ela tem de começar a conversar com as outras pessoas que ela fala: ah, há gente com mais experiência em pneumo?

P4 - [relatando uma vivência] A gente com medo tão grande de ser profissional, né, muito grande. Até você conseguir relaxar... se você não tá num ambiente relativamente acolhedor, né, onde as pessoas desenvolvem processo de acolhimento, até de capacitação porque precisa, né, você não migra de academia pro serviço de saúde! 
A produção de sentidos por estudantes...

P1 - Primeiro, supernova, né, cheia de medo, cheia de culpa, eu ouvia as vozes dos meus professores na minha cabeça e não tinha... a enfermagem era horrivel, tenebrosa em [nome do hospital], era um abandono!

Essas experiências relatadas indicam a aproximação das vivências da protagonista com os espectadores. Isso diz respeitos, principalmente, às leituras na dimensão de leitura discriminação. Essas interações foram predominantes na discussão e, em maior parte, identificou como alguns aspectos das questões principais apresentadas no vídeo, ainda persistem como desafios à atuação em enfermagem. Então os participantes reconhecem que se trata de um momento passado, mas entendem que os desafios são os mesmos. Os espectadores identificaram na narrativa desafios que ainda enfrentam em sua atuação.

P3 - Me deu assim um desconforto de vê-los... de ver como a gente ainda tá nessa tecla de encontro e desafio na prática, né, você trabalha numa área e tem dificuldade de dialogar com as outras quando você tem... tá com um usuário que precisa de cuidado também de outra clínica e... ou então ali mesmo no contexto dele como é que é, por exemplo, essa patologia na história de vida dele se fala muito nisso como uma dificuldade..

Eles reconheceram o universo filmico como antigo, mas como entendem que o vídeo representa um contexto de disputas que ainda são enfrentadas. Isso explicita uma leitura no eixo imersão da dimensão discriminação, como imerso, apesar da inicial resistência a alguns recursos estéticos. Já no eixo distanciamento, o vídeo recebeu poucas referências como algo construído. Por exemplo, a crítica foi apontada à conduta da protagonista no atendimento e não como o vídeo construiu isso. Essa percepção só é explicitada quando os espectadores são convidados, na parte final da discussão, a dizer o que fariam de diferente se pudessem refazer o vídeo assistido, principalmente por diferenças contextuais na atualidade. Desse modo, é possivel caracterizar a leitura nesse eixo como não distanciada. No trecho a seguir estão mais algumas falas que sustentam essa percepção. 
P2 - E aí, fazendo no nosso tempo e tal, mas é uma coisa que muda muito a lógica, né... o tempo desse consumo do serviço, não só pelo usuário, mas também pelo trabalhador da saúde, nessa coisa de pápum-pá-pum-pá-pum... tem quase dez anos que a gente tem um processo no Ministério Público que até hoje a gente não tem sentença da família, a gente tem PMF, Programa Médico da Família. Então, não dá para ver esse video e não pensar na minha realidade também em relação ao nosso municipio, enfermeira que não pode fazer preventivo.

P1 - Hoje, tem muitas variáveis no universo produtivista que a gente tá vivendo dentro dessa lógica, super, super neoliberal, né e que altera completamente esse video, né, porque a lógica hoje é outra.

P6 -... muitas enfermeiras fazem isso como estratégia em Clinica da Familia, elas fazem um atendimento coletivo e ai vai toda... pra poder cumprir meta, né, porque ai entra produção, você que trabalhou. É difícil, gente.

Nos trechos destacados nos parágrafos anteriores, também é possivel perceber que os espectadores superaram eventuais obstáculos nas leituras da dimensão discriminação, para produzir, na dimensão compreensão, leituras que convergentes ao as leituras pretendidas pelos produtores, ou seja, convergentes ao significado preferencial. A proximidade da estória com suas experiências profissionais foi um aspecto influente na produção dessas leituras. Esse aspecto, dificultou que as dimensões de compreensão e posição fossem analisadas separadamente. Por estarem completamente de acordo com o discurso político que deu origem ao vídeo, aquilo que os espectadores expressaram entender sobre o vídeo já transparecia, evidentemente, a sua posição em relação ao perspectiva defendida no vídeo. Assim, aquilo que eles entenderam do vídeo é muito próximo de como eles pensam as questões apresentadas no vídeo, justamente por ser bastante próximo ao que eles vivenciaram em suas trajetórias. Nos trechos a seguir destacados esses pontos são exemplificados

P2 - De modo geral, eu notei que tem tantas coisas que a gente ainda fala hoje que a gente pensa que é tão agudo, mas ai a gente vê que não é, que crônico. Foi em oitenta e dois que você falou que foi feito o vídeo?

P1 - Ela fez com perspectiva biopsicosocial formada na década de oitenta.

P5 - a gente tem que se aproximar mais da comunidade, da associação de moradores. Hoje a gente vê uma participação maior, né, e o trabalho da saúde pública pra fazer no setor psiquiátrico e é sempre com o enfermeiro do PMF com um agente comunitário, enfim que eles Interfaces da Educ., Paranaíba, v.11, n.31, p. 606 - 624, 2020 
A produção de sentidos por estudantes...

conhecem todo mundo que a gente para pra falar com todo mundo no meio do caminho, então assim, existe um feedback muito grande e isso, pelo menos ali, analisando a fala dos personagens, por isso é... né, acho que a comunidade, a associação dos moradores que muitas vezes a gente precisa fazer... como precisa fazer o trabalho de sensibilização, no caso da saúde mental porque a comunidade não tava aceitando aquele paciente que tá translocado e ai a gente consegue marcar através...

P2 - Me deu assim um desconforto de vê-los... de ver como a gente ainda tá nessa tecla de encontro e desafio na prática, né, você trabalha numa área e tem dificuldade de dialogar com as outras quando você tem... tá com um usuário que precisa de cuidado também de outra clínica e... ou então ali mesmo no contexto dele como é que é, por exemplo, essa patologia na história de vida dele se fala muito nisso como uma dificuldade...

P1-...acho que os alunos ainda acham que esse saber, que é um saber dialogado, né, saber que passa através das conversas, da compreensão do outro, o relacionamento interpessoal, que isso não tem valor nenhum, né, até que eu possa pegar uma medicação na mão e enfiar no paciente, a verdade é essa, né! Administrar o paciente pela via mais complexa possivel, né, e se valendo de alta tecnologia pra isso. Até mesmo a administração de medicação (incompreensível) porque na saúde pública existe toda uma padronização, o enfermeiro pode prescrever as medicações que estão no programa da saúde pública, ele também... é um video extremamente educativo sobre as possibilidades de ser enfermeiro no campo da saúde pública, né, mas...

Assim, caracterização da dimensão posição, é possivel destacar a identificação da defesa da perspectiva biopsicossocial de atenção em saúde, da importância do trabalho em rede, da equipe multidisciplinar e da valorização do trabalho junto à comunidade como pontos relevantes para essas leituras, justamente pela concordância dos espectadores com essa perspectiva. Essas demandas políticas cotidianas enunciadas pelos espectadores ao assistir ao vídeo, parecem ter preenchidos lacunas na narrativa e influenciado o que eles compreenderam. Assim, a dimensão compreensão pode ser caracterizada como convergente ao que foi intencionado pelos produtores, contudo não se pode ter certeza se os espectadores se atentaram a aspectos do filme ou as suas expectativas aos discursos (relativos à dimensão posição) apresentados no vídeo.

No polo da produção, observamos que o vídeo educativo analisado foi construído a valorizar o entendimento acerca da importância da consulta de enfermagem para a produção da saúde da população e à percepção de que nem sempre há o devido preparo do enfermeiro para tal, o vídeo valorizou a 
Américo de Araujo Pastor Junior, Luiz Augusto Coímbra de Rezende Filho e Cláudia Mara de Melo Tavares

apresentação de situações problemas e de respostas a essas situações. Essa dinâmica se desenvolveu de modo encadeado e centrado nas situações vivenciadas pela protagonista, esta construída para favorecer a abordagem de espectadores enfermeiros com algum grau de inexperiência na prática da consulta.

As leituras produzidas foram marcadas principalmente pela proximidade do alinhamento ideológico dos espectadores e do vídeo. Essa proximidade contribui para a superação de poucos obstáculos estéticos oferecidos pelo vídeo e possibilitou aos espectadores a entrarem constantemente no universo filmico. Esse universo, coerente com o universo profissional dos espectadores, teve suas eventuais lacunas preenchidas pelos espectadores. Com isso, um vídeo produzido 27 anos antes dessa exibição estudada não trouxe impedimentos estéticos que tornassem a narrativa pouco verossímil aos espectadores. A permanência das lutas políticas que têm como pauta a valorização da perspectiva biopsicossocial, da humanização do atendimento, a importância do trabalho em equipe multiprofissional e o empoderamento dos sujeitos/comunidades.

Nesse sentido, as leituras de aceitação na dimensão de leitura Posição, juntamente às vivências profissionais dos espectadores, influenciaram a produção de leituras de imersão e não-distanciamento na dimensão Discriminação. Ambas caracterizações, contribuíram para inferir leituras convergentes na dimensão Compreensão. Assim, nas três dimensões analisadas, as leituras tenderam fortemente a ocorrer de acordo ao significado preferencial.

Com base nas dimensões de leituras analisadas, foi possivel notar que quase a totalidade dos expectadores se identificaram com a enfermeira novata, mobilizaram suas próprias experiências profissionais para sustentar sua experiência com o filme e reforçaram o discurso defendido pelo filme. A construção da personagem protagonista valorizou aspectos de insegurança e capacidade de reflexão, aspectos que favoreceram a identificação dos espectadores com a personagem.

Em referência às três perguntas norteadoras da análise do modo de endereçamento, os espectadores pensam ser profissionais de enfermagem em Interfaces da Educ., Paranaíba, v.11, n.31, p. 606 - 624, 2020 
A produção de sentidos por estudantes...

constante desenvolvimento e na luta política por um sistema de saúde mais justo e eficiente, o que coincide fortemente com o que o vídeo "pensa" e "espera" de seus potenciais espectadores. Assim, os dados produzidos indicam que os profissionais de enfermagem (sobretudo os iniciantes), ao discutir o filme e mobilizar suas vivências para a produção de sentidos a partir do filme, demonstraram uma percepção crítica de aspectos implicados na consulta de enfermagem. Identificaram transformações e desafios ainda presentes, bem como indicaram caminhos para a transformação desse quadro.

\section{Considerações finais}

Diante dos resultados aqui apresentados e discutidos, foi possivel identificar a importância dos discursos circulantes na formação em enfermagem e na atuação crítica e reflexiva de profissionais de enfermagem para uma práxis atenta às demandas da cuidado nos sistema de saúde nacional. A partir do vídeo, os espectadores revisitam suas experiências, questionaram suas práticas, repensaram sua atuação macro e micro, fazendo criticas importantes ao funcionamento do sistema de saúde. Assim, foram as reflexões sobre as vivências bem como uma formação atenta às lutas politicas da classe que ofereceram recursos para que os espectadores pudessem produzir sentidos mais próximos as expectativas dos produtores e, principalmente, às demandas sociais do serviço de saúde. A perspectiva ideológica foi a mais marcante e determinante na produção das leituras.

Apesar de alguns poucos recentes avanços em contexto nacional, ainda persistem demandas por transformações no sistema de saúde, no atendimento e na formação de profissionais. Assim, mesmo com o distanciamento histórico, a permanência das pautas de lutas políticas na enfermagem (e na saúde), além dos desafios pessoais experimentados em suas trajetórias profissionais, fizeram o que as leituras dos espectadores fossem bastante próximas às expectativas dos produtores, em todas as dimensões analisadas. Os espectadores se demonstraram conscientes e ativos em sua produção de sentido. Produziram suas leituras próximas às expectativas dos produtores, sem aceitar passivamente o que era apresentado pelo vídeo. Interfaces da Educ., Paranaíba, v.11, n.31, p. 606 - 624, 2020 
Américo de Araujo Pastor Junior, Luiz Augusto Coímbra de Rezende Filho e Cláudia Mara de Melo Tavares

Nessas leituras, empreenderam ajustes que os ajudaram a superar as diferenças histórias estéticas do contexto de produção do vídeo, bem como identificaram proximidades.

Estudos como este que aqui apresentamos contribuem para orientar e inspirar usos mais consistentes de vídeo em sala de aula e em outros espaços formativos, isso pois oferece uma percepção sobre usos concretos de filmes e vídeos acompanhadas de reflexões ancoradas nessa empiria. Tal aspecto contribui para o uso cada vez mais consciente desses recursos na educação. Assim, de modo central, possibilita compreender que levar o vídeo para a sala de aula não algo neutro, nem simples, mas altamente influenciado pelo contexto cultural, pelas tensões e demandas curriculares, além a vivências e expectativas/demandas de estudantes, estes espectadores ativos, produtores ativos de seu saber.

Evidentemente, os resultados e reflexões aqui construídas carecem de serem melhor desenvolvidas e articuladas com resultados de outras pesquisas que esperamos realizar e sugerimos que sejam realizadas por pesquisadores interessados nos tópicos de pesquisa que compõe o presente texto. Assim, é desejável que sejam realizados estudos que contemplem outras obras audiovisuais, contextos formativos e grupos de espectadores, sobretudo em diferentes niveis e tipos de formação em enfermagem.

\section{Referências bibliográficas}

BARDIN, L. Análise de Conteúdo. Lisboa: Edições 70, LDA. 2009.

BARRATT J. A focus group study of the use of video-recorded simulated objective structured clinical examinations in nurse practitioner education. Nurse educ. pract. v.10n.3p.170-175, 2010.

CONSULTA DE Enfermagem. CNCT-MS, NUTES/UFRJ. Brasil: Laboratório de Vídeo Educativo do NUTES/UFRJ, 1990. (22 min.), DVD, son., color.

ELLSWORTH, E. Modo de endereçamento: uma coisa de cinema, uma coisa de educação também. In: SILVA, T. (org.). Nunca fomos humanos: 
A produção de sentidos por estudantes...

metamorfoses da subjetividade contemporânea. Belo Horizonte: Autêntica, 2001.

FIESCHI L, BURLON B, DE MARINIS M. Teaching midwife students how to break bad news using the cinema: An Italian qualitative study. Nurse educ. pract. v.15 n.2 p.141-147, 2015.

HALL, S. Reflexões sobre o modelo de Codificação/Decodificação (entrevista com Stuart Hall). In: SOVIK, L. org. Da diáspora: identidades e mediações culturais. Belo Horizonte: Editora UFMG; Brasília: Unesco, p. 353-386, 2003.

HEWITT J, TOWER M, LATIMER S. An education intervention to improve nursing students' understanding of medication safety. Nurse educ. pract. v.15 n. 1, p.17-21, 2015

LEMKE, J. L. Textual Politics: Discourse and Social Dynamics. Londres: Taylor \& Francis, 2005.

OLIVEIRA et al. Filme no ensino-aprendizagem sobre pessoas com deficiência. Esc. Anna Nery (impr.). abr -jun; v.16 n.2, p.297-305, 2012

PASTOR JUNIOR, A. A.; REZENDE FILHO, L. A. C. ; PEREIRA, M. V. . Estudo da apropriação de um filme na educação médica. Revista Tecnologias na Educação, v. 14, p. 1-11, 2016.

REZENDE FILHO, L. A. C.; BASTOS, W.; PASTOR JUNIOR, A. A. ; PEREIRA, M. V. ; SA, M. B. . Contribuições dos estudos de recepção audiovisual para a educação em ciências e saúde. Alexandria (UFSC), v. 8, p. 143-161, 2015.

SCHRØDER, K. C. Making sense of audience discourses: Towards a multidimensional model of mass media reception. European Journal of Cultural Studies, v.3, n.2, p.233-258, 2000.

SILVA, J. P.; TAVARES, C. M. Integralidade: dispositivo para a formação crítica de profissionais de saúde. Trabalho, Educação e Saúde, v. 2 n. 2, p. 271-285, 2004

TAVARES et al. Cinema: estratégia de ensino-aprendizagem na disciplina de história da enfermagem. Universitas Humanas, Brasilia, v. 11, n. 2, p. 39-48, Interfaces da Educ., Paranaíba, v.11, n.31, p. 606 - 624, 2020 
Américo de Araujo Pastor Junior, Luiz Augusto Coímbra de Rezende Filho e Cláudia Mara de Melo Tavares

jul./dez. 2014

VANOYE, F.; GOLIOT-LÉTÉ, A. Ensaio sobre a análise filmica. Campinas: Papirus, 1994.

WORTH, S. The Uses of Film in Education and Communication. In: GROSS, L. (ed.). Studying Visual Communication. Philadelphia: University of Pennsylvania Press, p.108-133, 1981. 